\title{
ALLEVIATION OF CADMIUM STRESS IN THAI RICE CULTIVAR (PSL2) BY INOCULATION OF INDIGENOUS CADMIUM- RESISTANT MICROBIAL CONSORTIA
}

\author{
SEANG-ON, L. ${ }^{1}$ - MEEINKUIRT, W. ${ }^{2}$ - SAENGWILAI, P. ${ }^{3,4}-$ SAMINPANYA, S. ${ }^{5}-$ KOEDRITH, K..$^{1,6^{*}}$ \\ ${ }^{1}$ Faculty of Environment and Resource Studies, Mahidol University, 999 Phuttamonthon \\ District, Nakhon Pathom 73170, Thailand \\ ${ }_{2}^{2}$ Mahidol University, Nakhonsawan Campus, Nakhonsawan 60130, Thailand \\ ${ }^{3}$ Department of Biology, Faculty of Science, Mahidol University, Rama VI, Bangkok 10400, \\ Thailand \\ ${ }^{4}$ Center of Excellence on Environmental Health and Toxicology (EHT), CHE, Ministry of \\ Education, Bangkok, Thailand \\ ${ }^{5}$ Department of General Science, Faculty of Science, Srinakharinwirot University, 114 \\ Sukhumvit 23 Road, Bangkok 10110, Thailand \\ ${ }^{6}$ Institute of Environmental Medicine for Green Chemistry, Department of Life Science, \\ Dongguk University Biomedical Campus, 32, Dongguk-ro, Ilsandong-gu, Goyang-si, Gyeonggi- \\ do 820-410, South Korea \\ *Corresponding author \\ e-mail: preeyaporn.koe@mahidol.edu \\ (Received $11^{\text {th }}$ Jun 2019; accepted $25^{\text {th }}$ Oct 2019)
}

\begin{abstract}
This study was aimed at isolating indigenous soil bacteria exhibiting cadmium (Cd)-resistance, and characterizing their ability to improve growth and reduce $\mathrm{Cd}$ bioaccumulation of Thai rice (Oryza sativa L.) PSL2 seedlings. Repeated enrichment, microorganisms were selectively propagated from agricultural soils receiving dredged sediments that contained $\mathrm{Cd}$ at $30-50 \mathrm{mg} \mathrm{kg}^{-1}$, in Western Thailand. Over a range of 0-1,000 ppm, the enriched bacterial consortia had a maximum tolerance to $\mathrm{Cd}$ at $800 \mathrm{ppm}$. In batch cultures containing 50 or $100 \mathrm{ppm} \mathrm{Cd}$, they exhibited 53-56 and 69-78\% Cd removal, respectively. The inoculation of enriched consortia ameliorated $\mathrm{Cd}$ phytotoxicity by promoting rice biomass and growth, and lowering tissue $\mathrm{Cd}$ content upon high $\mathrm{Cd}$ exposure (50-100 ppm). 16S metagenomic analysis showed that at least the top bacterial phyla of Proteobacteria, Firmicutes, and Bacteroidetes were enriched in the naturally polluted topsoil microorganisms with dominant bacterial phyla including Planctomycetes, Proteobacteria, Acidobacteria, Verrucomicrobia, Bacteroidetes, Chloroflexi, Actinobacteria, Firmicutes, and Gemmatimonadetes. In the enriched consortia, certain predominant detoxifiers (e.g., Acinetobacter sp., Comamonas sp., Enterococcus sp., and Pseudomonas sp.) were explored at a finer taxonomic level among other detected genera. These results emphasized that indigenous soil $\mathrm{Cd}$-resistant microorganisms have potential to cope with metal stress and improve crop plant growth and yield for agricultural benefits.
\end{abstract}

Keywords: bioremediation, Cd-resistant bacteria, food safety, microbial community, rice seedling

\section{Introduction}

Biosphere pollution by heavy metals has risen due to industrial activities and extensive use of agrochemicals. Particularly in developing countries, unorganized industrialization and waste management significantly accelerate the release of heavy metals into the soil and water bodies (Sharma et al., 2008). Toxic metals such as cadmium (Cd) have been deposited on the surface soil via industrial operations such as mining and alkaline battery manufacturing. 
Cadmium confers carcinogenicity and mutagenicity, even at low concentrations. In addition, $\mathrm{Cd}$ can interfere with renal function by its accumulation in the proximal tubular cells and also cause bone demineralization (Bernard, 2008). In addition to its adverse health effects, excessive $\mathrm{Cd}$ levels in the soil cause plant growth retardation, symbiosis interference, and crop yield reduction (Wani et al., 2007).

Soil pollution is one of the main factors causing $\mathrm{Cd}$ contamination in rice grains and human exposure via the food chain, indicating that a key point is to remedy $\mathrm{Cd}$ pollution from the paddy area, in order to minimize plant $\mathrm{Cd}$ uptake from soil and reduce its bioaccumulation in rice grains (Deng et al., 2014). Remarkably high levels of $\mathrm{Cd}$ in agricultural soils have been detected in the Padaeng zinc mining area of the southeast region of Mae Sot District, Tak Province, Thailand (Simmons et al., 2003, 2005). This has become a major concern since the International Water Management Institute demonstrated significant $\mathrm{Cd}$ contamination in rice grains and paddy soils in this province (Simmons et al., 2003). These Cd levels (ranging from 3.4-284.0 mg kg${ }^{-1}$ in the agricultural areas) are much higher than the European Community limit of $3 \mathrm{mg} \mathrm{kg}^{-1}$, posing high risk to the environment and human health (Swaddiwudhipong et al., 2012). Therefore, it is essential to remediate Cd-polluted soil in order to alleviate phytotoxicity, improve crop yield, and ultimately prevent direct human exposure.

A number of physicochemical approaches have been utilized for the reduction of toxicity and recovery of polluted agricultural sites. Nevertheless, bioremediation with use of indigenous heavy metal-resistant microorganisms conferring heavy metal removal and plant growth promoting potential would be a cost-effective choice for sustainable agricultural benefits (Govindasamy et al., 2011). The main issue is selection of indigenous heavy metal resistant microorganisms and their implementation in the contaminated area in a sustainable, ecologically friendly manner. Some soil microorganisms playing a dual role in both $\mathrm{Cd}$ resistance and plant growth promotion would be greatly in demand when applied in agricultural areas contaminated with heavy metal, as has been described for example,

Variovorax, Rhodococcus, Flavobacterium, Pseudomonas, Klebsiella, Bacillus, Stenotrophomonas, Serratia, Leifsonia and Enterobacter (Ahmad et al., 2014, 2015; Belimov et al., 2005; Etesami, 2018; Mitra et al., 2018; Sharma and Archana, 2016). Metal tolerance of plants can be improved by selection of the crop species; however, microorganisms conferring metal immobilizing abilities would be potentially applied to minimize pollutant uptake (Kuffner et al., 2010).

Rather than a single microbial isolate, biofilm-like indigenous soil microorganisms having relatively high $\mathrm{Cd}$ tolerance and rice growth promotion would be useful for longterm management and recovery of the metal-polluted rice paddy. The objective of the present study was to isolate indigenous Cd-resistant microbial consortia from the contaminated agricultural soils by repeated enrichment culture, characterizing their $\mathrm{Cd}$ tolerance and -removal capacities, and assessing their effects on the seed germination and seedling growth of Thai rice cultivar (Oryza sativa L.) PSL2, as well as tissue Cd content upon high Cd stress.

\section{Materials and methods}

\section{Study site}

Soil samples were collected from a $\mathrm{Cd}$ and zinc ( $\mathrm{Zn})$-contaminated agricultural area in Pha Dei Village, Mae Sot District, Tak Province, Thailand (N 16 40'35.9" E 98 37' $\left.37.4^{\prime \prime}\right)$ at an altitude of $197 \mathrm{~m}$. The study site is controlled by the subtropical monsoon 
climate with average annual temperature of $26^{\circ} \mathrm{C}$ and average annual precipitation of $1,448 \mathrm{~mm}$. This rice paddy is usually cultivated either with rice-corn or rice-bean crops in a cropping year. For enrichment and isolation of indigenous $\mathrm{Cd}$ resistant microorganisms, soil samples were collected from the agricultural area and alongside an irrigation streamline adjacent to the rice paddy in a single site (the sampling site is shown in Fig. Al in the Appendix). Thirty-six samples of topsoil ( $<20 \mathrm{~cm}$ in depth, ca. $1 \mathrm{~kg}$ in weight each) were collected from May to July 2016 (rainy season) and January to March 2017 (dry season).

\section{Physicochemical studies of Cd-contaminated soil}

The topsoil samples were collected as described above. Soil samples were divided into 2 main portions: one for physicochemical analyses and another one for the culture enrichment. The following soil properties were determined: $\mathrm{pH}$ (1:5 soil/water suspensions) using field-moist samples and a $\mathrm{pH}$ meter; electrical conductivity (EC) using an EC meter; organic matter (OM) content by wet oxidization and titration according to the modified Walkley-Black procedure (Nelson and Sommers, 1996); and oxidationreduction potential (ORP) using field-moist samples and an ORP meter; and cation exchange capacity (CEC) was tested after leaching with $1 \mathrm{~N}$ ammonium acetate $\left(\mathrm{NH}_{4} \mathrm{OAc}\right)$ buffer.

The collected soil samples were oven-dried and crushed using an agate mortar before being passed through a 200-mesh sieve. The samples then were analyzed for total $\mathrm{Cd}$ concentration in a flame atomic absorption spectrophotometer (FAAS, AAnalyst 200, PerkinElmer ${ }^{\circledR}$ ) after $\mathrm{HNO}_{3}$ digestion (APHA, AWWA, and WEF, 2005). Bioavailable soil $\mathrm{Cd}$ was determined by FAAS after extraction with $0.05 \mathrm{M}$ diethylene triamine pentaacetic acid (DTPA) (APHA, AWWA, and WEF, 2005). Total nitrogen (N) was measured by the Kjeldahl method (Blake, 1965). Extractable phosphorus (P) and potassium $(\mathrm{K})$ were determined by the Bray II method and extraction with neutral $\mathrm{NH}_{4} \mathrm{OAc}$ buffered to $\mathrm{pH} 7.0$, respectively (Bray and Kurtz, 1945). Soil texture was examined with the hydrometer (Allen et al., 1974). Physicochemical characteristics of soil samples are listed in Table 1.

Table 1. Selected physicochemical properties of the contaminated agricultural soil

\begin{tabular}{|c|c|c|c|c|}
\hline \multirow{2}{*}{ Parameter } & \multicolumn{2}{|c|}{ Rainy season } & \multicolumn{2}{|c|}{ Dry season } \\
\hline & $\# 1$ & $\# 2$ & $\# \mathbf{3}$ & $\# 4$ \\
\hline Temperature $\left({ }^{\circ} \mathrm{C}\right)$ & 24 & 25 & 26 & 27 \\
\hline $\mathrm{pH}$ & 7.22 & 7.44 & 5.39 & 6.73 \\
\hline $\mathrm{ORP}(\mathrm{mV})$ & 400 & 300 & 100 & 200 \\
\hline $\mathrm{EC}\left(\mathrm{dS} \mathrm{m} \mathrm{m}^{-1}\right)$ & 0.48 & 0.38 & 0.28 & 0.34 \\
\hline $\mathrm{CEC}\left(\mathrm{cmol} \mathrm{kg}^{-1}\right)$ & 18.2 & 19.4 & 13.8 & 12.6 \\
\hline OM (\%) & 1.99 & 1.85 & 1.38 & 1.49 \\
\hline Total N $\left(\mathrm{mg} \mathrm{kg}^{-1}\right)$ & 2943 & 2846 & 2445 & 2628 \\
\hline Extractable $\mathrm{P}\left(\mathrm{mg} \mathrm{kg}^{-1}\right)$ & 11.0 & 13.0 & 9.0 & 8.0 \\
\hline Extractable $\mathrm{K}\left(\mathrm{mg} \mathrm{kg}^{-1}\right)$ & 210.0 & 190.0 & 170.0 & 150.0 \\
\hline Total Cd $\left(\mathrm{mg} \mathrm{kg}^{-1}\right)$ & 52 & 45 & 28 & 41 \\
\hline Extractable $\mathrm{Cd}\left(\mathrm{mg} \mathrm{kg}^{-1}\right)$ & 5.5 & 4.9 & 4.6 & 3.8 \\
\hline
\end{tabular}

Enumeration of total cells and of cultivable microorganisms in the polluted soils 
The total microbial cells isolated from the original soil samples were enumerated by fluorescent blue dye Hoechst ${ }^{\circledR} 33342$ staining method, as previously described by Brunk et al. (1979) with some modifications. Ten grams of each soil sample was resuspended with $90 \mathrm{ml}$ PBS buffer. The suspension was stirred for $30 \mathrm{~min}$ at $200 \mathrm{rpm}$, sonicated in a sonication bath for $5 \mathrm{~min}$, and then centrifuged at 3,000 rpm for $5 \mathrm{~min}$. The supernatant was subjected for enumeration of total cells.

To determine the cell concentration of cultivable bacteria by the viable plate count technique, they were first inoculated in nutrient broth and incubated at $30{ }^{\circ} \mathrm{C}, 100 \mathrm{rpm}$ for 18 h. Each serially diluted cell suspension was subsequently spread on nutrient agar plates without and with $\mathrm{CdCl}_{2}$ at 50 and $100 \mathrm{ppm}$. After $24 \mathrm{~h}$ incubation at $30^{\circ} \mathrm{C}$, colonies of $\mathrm{Cd}$ resistant bacteria were counted and referred to as colony forming units per $\left.\mathrm{ml}^{(\mathrm{CFU} \mathrm{ml}}{ }^{-1}\right)$.

\section{Enrichment and isolation of Cd-resistant bacteria}

For enriching the Cd-resistant bacteria, the first $5 \mathrm{~g}$ of each sample was added to $95 \mathrm{ml}$ of nutrient broth (NB, $0.5 \%$ peptone, $0.3 \%$ meat extract, $\mathrm{pH} 7.0$ ) containing 50 or $100 \mathrm{ppm}$ cadmium chloride $\left(\mathrm{CdCl}_{2}\right)$. After 2 weeks of incubation at $30{ }^{\circ} \mathrm{C}$, the bacteria were cultured on nutrient agar plates (NA, nutrient broth and $1.5 \%$ agar) supplemented with $\mathrm{CdCl}_{2}$ for 72 $\mathrm{h}$ at $30{ }^{\circ} \mathrm{C}$. The colonies of Cd-resistant bacteria were quantified as colony forming units per $\mathrm{ml}\left(\mathrm{CFU} \mathrm{ml} \mathrm{m}^{-1}\right)$. Each single bacterial colony with different morphology was then streaked onto agar medium for $24 \mathrm{~h}$ at $30^{\circ} \mathrm{C}$.

\section{S-Metagenomic analysis of the Cd-resistant consortia}

Bacterial diversity and composition of the enriched consortia in comparison to the originally polluted soil consortia were analyzed using $16 \mathrm{~S}$ rRNA gene Illumina MiSeq sequencing. Total genomic DNA was extracted from $0.5 \mathrm{~g}$ of frozen soils and $10 \mathrm{ml}$ of the enriched culture (three replicates per treatment) using QIAamp ${ }^{\circledR}$ DNA Stool Mini Kit (Qiagen, Germany) according to the manufacturer's instructions with some modifications. The 16S rDNA (V3-V4) universal bacterial primers containing the Illumina overhang adapter sequences (as underlined) 341F (5' - TCGTCGGCAGCGTCAGATGTGTATAA GAGACAGCCTACGGGNGGCWGCAG) and 805R (5'- GTCTCGTGGGCTCGGAGA TGTGTATAAGAGACAGGACTACHVGGGTATCTAATCC) were utilized for PCR amplification (Herlemann et al., 2011). The PCR mixtures $(25 \mu \mathrm{l})$ contained $12.5 \mu \mathrm{l}$ of $2 \mathrm{x}$ KAPA HiFi Hot Start Readymix (KAPA Biosystems, USA), $5 \mu 1$ of each primer $(1 \mu \mathrm{mol}$ $\left.\mathrm{l}^{-1}\right)$ and $2.5 \mu \mathrm{l}$ of target DNA $\left(5 \mathrm{ng}^{-1} \mathrm{l}^{-1}\right)$. The PCR cycling conditions consisted of an initial denaturation step at $94^{\circ} \mathrm{C}(3 \mathrm{~min})$, followed by 25 cycles of $98^{\circ} \mathrm{C}(20 \mathrm{~s}), 55^{\circ} \mathrm{C}(30 \mathrm{~s})$ and $72{ }^{\circ} \mathrm{C}(30 \mathrm{~s})$ and a final elongation at $72{ }^{\circ} \mathrm{C}(5 \mathrm{~min})$. The PCR products were cleaned-up on AMPure XP beads (Agencourt Bioscience, USA). The purified amplicons (550-bp fragments) were submitted to the Omics Sciences and Bioinformatics Center (Chulalongkorn University, Bangkok, Thailand) for paired-end sequencing on the Illumina MiSeq platform.

Subsequently, the purified 16S amplicons were then indexed using 2X KAPA hot-start ready mix and $5 \mu \mathrm{l}$ of each Nextera XT index primer in a $50 \mu \mathrm{l}$ PCR reaction, followed by 8-10 cycles of PCR amplification. The PCR cycling was set as aforementioned. Next, the indexed 16S amplicons were purified on AMPure XP beads (Agencourt Bioscience, USA), pooled and diluted to a final loading concentration of $4 \mathrm{pM}$. Cluster generation and 250-bp paired-end read sequencing were done on an Illumina MiSeq using the MiSeq Reagent Kit at the Omics Sciences and Bioinformatics Center (Chulalongkorn University, Bangkok, 
Thailand). Amplicon sequence analysis was performed with QIIME version 1.9.0. (Caporaso et al., 2010). All sequence reads were sorted based on their unique barcodes, trimmed for sequence quality, and clustered at $97 \%$ identity for operational taxonomic units (OTUs). The UCHIME algorithm was used to discard chimera sequences (Edgar et al., 2011). The microbial diversity index in terms of diversity (Shannon index) and richness (Chao1 index) were then computed using the MOTHUR (Schloss et al., 2009). To study the microbial composition and diversity, the Shannon diversity index, an estimator of species richness and diversity using a natural logarithm, accounts for both abundance and evenness of the taxa present, while Chao1 richness estimator is used to estimate diversity from abundance data and number of rare taxa missed from under-sampling.

\section{Determination of maximum tolerance concentration (MTC) of Cd}

In brief, the enriched consortia and isolated strains were inoculated in nutrient broth supplemented with $\mathrm{CdCl}_{2}$ (50 to $\left.1,000 \mathrm{ppm}\right)$. After $18 \mathrm{~h}$ incubation at $30^{\circ} \mathrm{C}$, each culture was then spread on nutrient agar plates with $\mathrm{CdCl}_{2}$ at the same concentrations. The highest concentration of metal ions at which growing colonies of bacteria were observed was defined as the maximum tolerance concentration (MTC) of $\mathrm{Cd}$ for the tested bacteria. Media without $\mathrm{CdCl}_{2}$ serves as controls. All experiments were performed in triplicate.

\section{Determination of Cd removal capacity of the enriched consortia in batch culture}

Effect of the enriched Cd-resistant microbial consortia on reduction of water-soluble $\mathrm{Cd}$ concentration in culture medium was examined according to the method of Chen et al. (2008) with some modifications. In brief, the enriched consortia were initially cultivated in nutrient broth, harvested by centrifugation, and washed twice with sterile deionized water. Cell pellets were then resuspended in the sterile water. Triplicate flasks of nutrient broth supplemented with 50 or $100 \mathrm{ppm} \mathrm{CdCl}_{2}$ were inoculated with microbial suspension of either the enriched consortium or the selected single strain, compared to microbialinoculated culture without $\mathrm{Cd}$ and the control (uninoculated culture with $\mathrm{Cd}$ addition). After $24 \mathrm{~h}$ incubation at $30^{\circ} \mathrm{C}$, the microbial growth in the cultures was measured at the optical density $\left(\mathrm{OD}_{600}\right)$ for quality control (data not shown). The cell pellets were harvested by centrifugation and their dry cell weight were measured while the water-soluble $\mathrm{Cd}$ concentration in the supernatant was then determined with an AAnalyst 200 Perkin-Elmer ${ }^{\circledR}$ FAAS. The percentage of Cd removal of each culture was calculated using Equation 1:

$$
\% \text { Cd removal }=\frac{C I-C F}{C I} \times 100
$$

where $\mathrm{CI}$ is the initial $\mathrm{Cd}$ concentration in the medium; $\mathrm{CF}$ is the $\mathrm{Cd}$ concentration that remains in the supernatant.

\section{Effect of Cd-resistant bacteria on rice seedlings using the filter paper system}

The plant root/shoot elongation promoting ability of the enriched consortia was assessed using the modified root elongation assay of Belimov et al. (2001). Bacteria were grown on nutrient broth containing $\mathrm{Cd}$ for $48 \mathrm{~h}$ at $30^{\circ} \mathrm{C}$ and resuspended to $5 \times 10^{7}$ cells ml ${ }^{-1}$ in sterile deionized water. Six milliliters of the bacterial suspensions at final concentration $1 \times 10^{6}$ cells $\mathrm{ml}^{-1}$ or sterile water (uninoculated control) were added to glass Petri dishes containing filter paper that was soaked with 50 or $100 \mathrm{ppm} \mathrm{CdCl}_{2}$ (final concentration) in comparison to bacterial inoculation without $\mathrm{CdCl}_{2}$ as control. The seeds of rice cultivar (Oryza sativa 
L.) PSL2 were surface-sterilized with a mixture of ethanol and $30 \% \mathrm{H}_{2} \mathrm{O}_{2}$ (1:1) for $20 \mathrm{~min}$, washed twice with sterile water and placed on the wetted filter paper. Root/shoot length and number of fibrous roots of seedlings were measured after incubation at $28{ }^{\circ} \mathrm{C}$ for 7 and 14 days in the dark. Dry biomass was determined after plant materials were oven-dried at $80{ }^{\circ} \mathrm{C}$ for 4 days prior to weight determination. The assay was repeated two times with six dishes $\left(20\right.$ seeds dish $\left.^{-1}\right)$ for each treatment.

\section{Effect of Cd-resistant bacteria on Cd accumulation of rice tissues}

The plant root/shoot Cd content was measured according to the method of Ihnat (2000). After 14 days of incubation at $28{ }^{\circ} \mathrm{C}$ in the dark, rice seedlings grown in $\mathrm{Cd}$ with or without bacteria inoculation were washed twice with sterile water, oven-dried at $80^{\circ} \mathrm{C}$ for $2 \mathrm{~h}$, and weighed prior to $\mathrm{Cd}$ quantification. The $\mathrm{Cd}$ concentration of 30 rice seedlings per treatment was measured using an AAnalyst 200 Perkin-Elmer ${ }^{\circledR}$ FAAS after $\mathrm{HNO}_{3}$ digestion $($ APHA, AWWA, and WEF, 2005). The assay was performed in triplicate.

\section{Statistical analysis}

Data were subjected to the statistical analysis using the student's t-test. The treatment means were compared by setting the significant difference at the $5 \%$ probability level $(P$ value $\leq 0.05)$.

\section{Results}

\section{Enrichment and isolation of Cd-resistant soil microorganisms}

During the selection of Cd-resistant microorganisms, thousands of growing colonies were observed on nutrient agar plates containing 50-100 ppm $\mathrm{CdCl}_{2}$. Fluorescent nuclear staining revealed that total microbial abundance in the naturally polluted soils ranged from $1.8 \times 10^{8}-8.9 \times 10^{9}$ cells ml $^{-1}$ after Hoechst ${ }^{\circledR} 33342$ dye blue staining (Fig. 1). The direct cultivable microbial abundance in the polluted soils ranged from $1-5 \times 10^{7} \mathrm{CFU}$ $\mathrm{ml}^{-1}$ after cultivation on nutrient agar plates without $\mathrm{CdCl}_{2}$. After 2 weeks of repeated enrichment culture, the average number of enriched microorganisms was found to be 1.5-

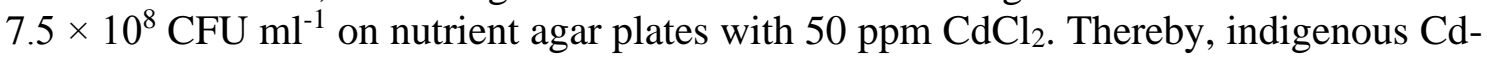
resistant microbial consortia were successfully isolated by the repeated enrichment method and sequential dilution technique.

\section{Relative abundance and composition structure of the enriched consortia}

The relative abundance and composition of the enriched consortia were assessed and compared to the originally polluted topsoil consortia by a $16 \mathrm{~S}$ metagenomic sequencing approach. Table 2 shows the alteration in the functional diversity indices of the enriched consortia, in comparison to the polluted topsoil consortia. Diversity indices of the enriched consortia were altered when compared to the naturally polluted topsoil samples, as shown by the decrease in the Shannon diversity index and the Chao1 richness estimator. 

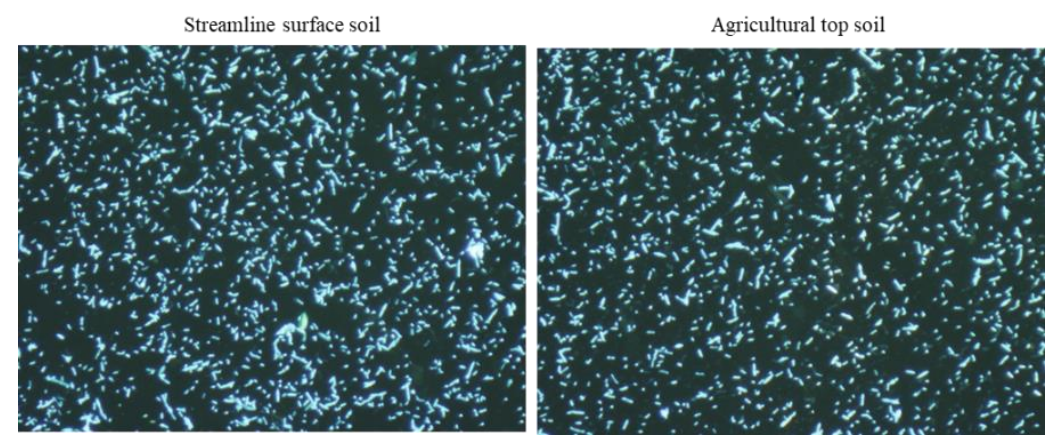

Figure 1. Representative images showing total cellular abundance of indigenous soil microbial consortia. Total microbial cells were directly collected from the Cd polluted soils: streamline surface soil (left panel) and agricultural top soil (right panel). Microbial DNA was stained with Hoechst 33342 fluorescent dye, and observed under a fluorescence microscope at 1,000× magnification

Table 2. Summary of bacterial 16S sequencing data and diversity estimates for each sample

\begin{tabular}{c|c|c|c|c|c|c}
\hline Sample & Season & Reads & OTUs & Coverage & Chao1 & Shannon \\
\hline TS\#1 & Rainy & $62157 \pm 6091$ & $2698 \pm 319$ & 0.998 & 7740.87 & 10.86 \\
TS\#2 & Rainy & $65129 \pm 5982$ & $2749 \pm 258$ & 0.998 & 7772.27 & 10.98 \\
TS\#3 & Dry & $63269 \pm 7081$ & $2643 \pm 321$ & 0.997 & 5700.46 & 10.84 \\
TS\#4 & Dry & $61709 \pm 7109$ & $2763 \pm 289$ & 0.997 & 6759.19 & 10.85 \\
\hline BC\#1 & Rainy & $60987 \pm 8305$ & $3019 \pm 196$ & 0.996 & $491.35^{* *}$ & $4.69^{* *}$ \\
BC\#2 & Rainy & $61268 \pm 7949$ & $2991 \pm 362$ & 0.995 & $551.72^{* *}$ & $4.75^{* *}$ \\
BC\#3 & Dry & $60106 \pm 8104$ & $3026 \pm 234$ & 0.995 & $470.77^{* *}$ & $4.42^{* *}$ \\
BC\#4 & Dry & $61232 \pm 7756$ & $2987 \pm 265$ & 0.996 & $474.97 * *$ & $4.60^{* *}$ \\
\hline
\end{tabular}

**Indicates respective significant difference at $P$-value $\leq 0.05$, by comparing the selected parameters (Chao1 richness or Shannon diversity estimator) of the bacterial enriched consortia (BC) to that of the original polluted topsoil (TS) samples. OTUs represent operational taxonomic units. BC indicates Cdresistant bacterial consortia after $\mathrm{Cd}$-added culture enrichment, and TS indicates topsoil samples originally contaminated with $\mathrm{Cd}$

Figure $2 a$ presents the relative abundances of the bacterial phyla in the polluted topsoil and the enriched consortia. Planctomycetes, Proteobacteria, Acidobacteria, Verrucomicrobia, Bacteroidetes, Chloroflexi, Actinobacteria, Firmicutes and Gemmatimonadetes were the most dominant phyla, accounting for $90 \%$ of the total bacterial $16 \mathrm{~S}$ rRNA gene sequences in the polluted topsoil. Planctomycetes occupied the highest proportions $(47.5 \%)$ of the bacterial sequences. Proteobacteria, Acidobacteria, Verrucomicrobia, Bacteroidetes, Chloroflexi, Actinobacteria, Firmicutes and Gemmatimonadetes were identified in all topsoil samples at cumulative relative abundance (ca.42.5\%). Approximately $2 \%$ of bacterial phyla were unassigned.

The consecutive addition of $\mathrm{Cd}$ at increasing concentrations (20-100 ppm) could select population of Cd-resistant bacterial phyla among other Cd-sensitive phyla. The $16 \mathrm{~S}$ metagenomic result showed that the 3 top phyla including Proteobacteria $(47.7 \%)$ Firmicutes (36.5\%) and Bacteroidetes (15.5\%) were markedly enriched relative to the original topsoil $(P$-value $\leq 0.05)$ (Fig. $2 a)$. The relative abundances of Proteobacteria, Firmicutes, and Bacteroidetes increased across the culture enrichment period, while those 
of Acidobacteria, Actinobacteria, Chloroflexi, Gemmatimonadetes, Planctomycetes, and Verrucomicrobia decreased. In the enriched consortia, predominant detoxifiers at finer taxonomic level of Proteobacteria (including Arcobacter sp., Comamonas sp., Pseudomonas sp., Acinetobacter sp., Stenotrophomonas sp., and Delftia sp.), Firmicutes (including Leuconostoc sp., Enterococcus sp., Lactobacillus sp., and Lactococcus sp.), and Bacteroidetes (including Wautersiella sp., Myroides sp., Cloacibacterium sp., Paludibacter sp.) were uncovered among other genera (Fig. 2b). The enriched microbial consortia were successfully established and subjected to subsequent characterization.
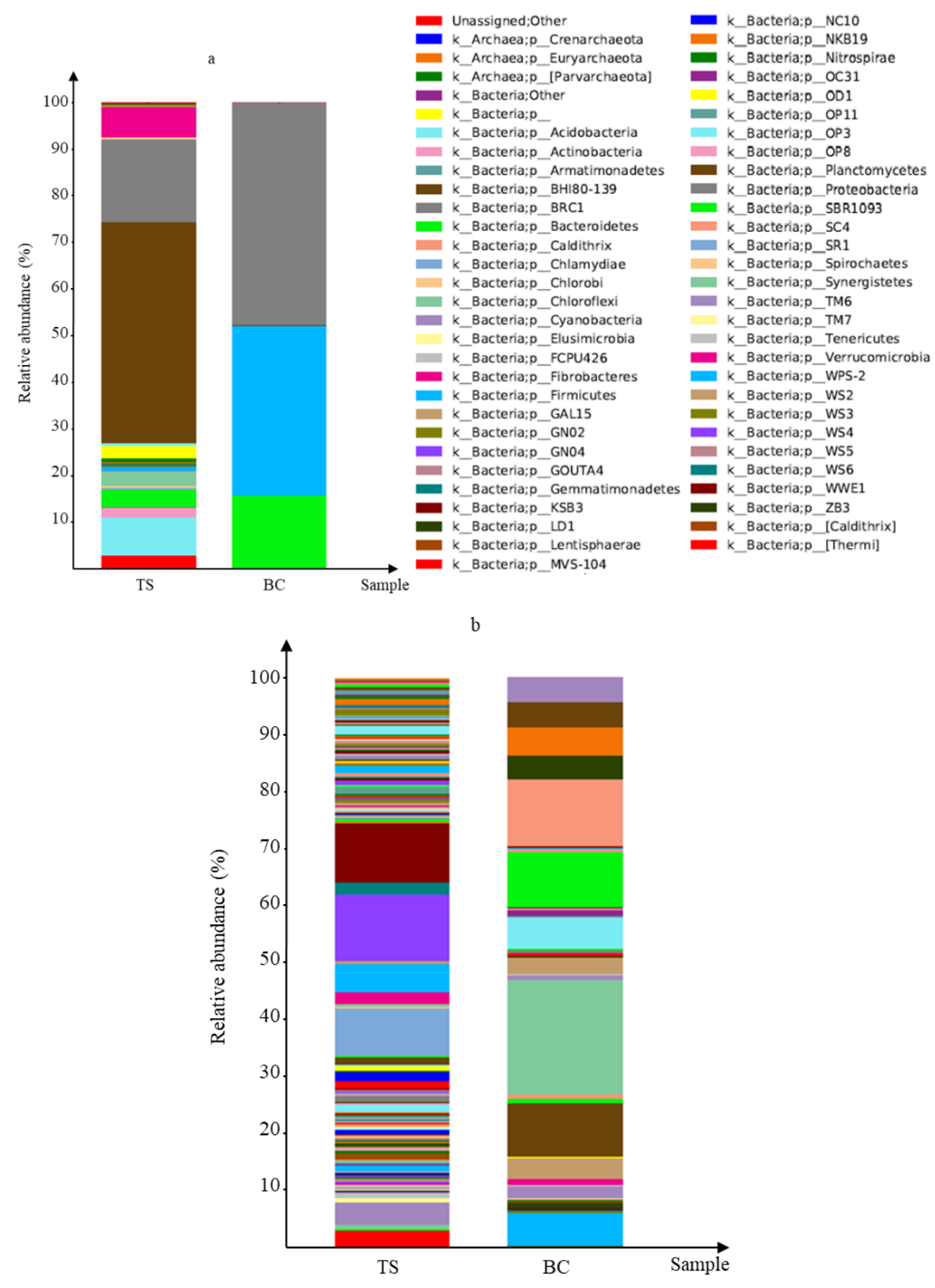

Figure 2. Representative images showing relative abundance levels of dominant bacterial phyla (a) and genera (b) in the contaminated topsoil (TS) and the enriched cadmium-resistant bacterial consortia $(B C)$ (cultivable Cd) based on 16 S metagenomic sequencing 


\section{Determination of maximum $C d$ tolerance and $C d$ removal capacity of the enriched consortia}

The maximum tolerance of the enriched microbial consortia toward $\mathrm{CdCl}_{2}(0-$ $1,000 \mathrm{ppm}$ ) were determined in comparison to that of selected single strains. Viable plate counts showed that the enriched consortia grew well and survived on nutrient agar containing $\mathrm{CdCl}_{2}$ up to $800 \mathrm{ppm}$ (Fig. A2 in the Appendix), while most of the isolated single strains could only grow on the media with much lower $\mathrm{CdCl}_{2}$ up to $200 \mathrm{ppm}$ (Fig. A3 in the Appendix).

Furthermore, the effect of enriched consortia on immobilization of toxic $\mathrm{Cd}$ in the batch culture was investigated. After $24 \mathrm{~h}$ incubation, the water-soluble Cd concentration in each supernatant was remarkably decreased upon inoculation of either enriched consortia or single isolates. In presence of $50 \mathrm{ppm} \mathrm{Cd}$, the enriched consortia had $\mathrm{Cd}$ removal capacities ranging from $19.3 \pm 0.9$ to $25.5 \pm 0.8 \mathrm{mg} \mathrm{g}^{-1}$ cell dry weight, equivalent to $52.8-56.3 \% \mathrm{Cd}$ removal (Table 3). At a higher Cd concentration of $100 \mathrm{ppm}$, the $\mathrm{Cd}$ removal capacities ranged from $37.4 \pm 1.2$ to $48.6 \pm 0.6 \mathrm{mg} \mathrm{g}^{-1}$ cell dry weight, equivalent to $68.7-77.5 \% \mathrm{Cd}$ removal (Table 3). This indicated that the inoculation of Cd-resistant microorganisms could reduce water-soluble level of toxic $\mathrm{Cd}$ in order to possibly overcome $\mathrm{Cd}$ toxicity in the culture, and that the exogenous addition of $\mathrm{Cd}$ affected $\mathrm{Cd}$ removal capacities of the enriched consortia.

Table 3. Cadmium removal capacity of indigenous $C d$-resistant bacterial consortia (BC) after batch culture in nutrient broth containing $\mathrm{CdCl}_{2}$ at 50-100 ppm

\begin{tabular}{|c|c|c|c|c|}
\hline $\begin{array}{c}\text { Microbial } \\
\text { culture sample }\end{array}$ & $\begin{array}{c}\text { Cd concentration } \\
(\mathbf{p p m})\end{array}$ & $\begin{array}{c}\text { Percentage of } \\
\text { Cd removal }(\%)\end{array}$ & $\begin{array}{c}\text { Cell dry } \\
\text { weight }(g)\end{array}$ & $\begin{array}{l}\text { Cd removal capacity }\left(\mathrm{mg} \mathrm{g}^{-1}\right. \\
\text { cell dry weight in average) }\end{array}$ \\
\hline BC\#1 & $\begin{array}{c}0 \\
50 \\
100\end{array}$ & $\begin{array}{c}0 \\
52.8 * * \\
71.9 * *\end{array}$ & $\begin{array}{l}0.22 \\
0.25 \\
0.19\end{array}$ & $\begin{array}{c}- \\
19.3 \pm 0.9 \\
37.4 \pm 1.2\end{array}$ \\
\hline $\mathrm{BC} \# 2$ & $\begin{array}{c}0 \\
50 \\
100 \\
\end{array}$ & $\begin{array}{c}0 \\
56.3 * * \\
68.7 * * \\
\end{array}$ & $\begin{array}{l}0.20 \\
0.22 \\
0.14 \\
\end{array}$ & $\begin{array}{c}- \\
25.4 \pm 0.8 \\
48.6 \pm 0.6\end{array}$ \\
\hline $\mathrm{BC} \# 3$ & $\begin{array}{c}0 \\
50 \\
100 \\
\end{array}$ & $\begin{array}{c}0 \\
55.8 * * \\
76.7 * *\end{array}$ & $\begin{array}{l}0.23 \\
0.26 \\
0.21\end{array}$ & $\begin{array}{c}- \\
21.2 \pm 0.4 \\
36.2 \pm 0.7\end{array}$ \\
\hline $\mathrm{BC} \# 4$ & $\begin{array}{c}0 \\
50 \\
100 \\
\end{array}$ & $\begin{array}{c}0 \\
53.2 * * \\
77.5 * * \\
\end{array}$ & $\begin{array}{l}0.20 \\
0.24 \\
0.17 \\
\end{array}$ & $\begin{array}{c}- \\
22.1 \pm 0.9 \\
45.3 \pm 0.7\end{array}$ \\
\hline Bacillus cereus & $\begin{array}{c}0 \\
50 \\
100\end{array}$ & $\begin{array}{c}0 \\
14.9 * * \\
24.5 * *\end{array}$ & $\begin{array}{l}0.21 \\
0.19 \\
0.12\end{array}$ & $\begin{array}{c}- \\
8.6 \pm 0.5 \\
19.7 \pm 0.4\end{array}$ \\
\hline
\end{tabular}

** Indicates respective significant difference at $P$-value $\leq 0.05$, by comparing the selected parameters of Cd-treated group to that of control (untreated group) at indicated concentrations of $\mathrm{CdCl}_{2}$. $\mathrm{BC}_{\text {indicates }}$ Cd-resistant bacterial consortia after $\mathrm{Cd}$-added culture enrichment

\section{Effect of Cd-resistant microbial consortia on rice germination and seedling growth toward high-concentration $C d$ in vitro}

Cadmium usually impairs plant growth, which is one indicator for evaluating plant ability in response to $\mathrm{Cd}$ stress. Inoculation with the enriched consortia was applied for 
germination and growth studies at seedling stage of the Thai rice cultivar PSL2 in the presence or absence of $\mathrm{Cd}$. After 7 days of incubation, the length of roots and shoots and number of fibrous roots were measured in rice seedlings treated with or without the enriched consortia inoculant, in comparison to a soil bacterium Bacillus-inoculated group and non-metal treated group (control) upon $\mathrm{Cd}$ exposure (either 50 or $100 \mathrm{ppm}$ ). The control rice exhibited normal growth (Fig. 3a; Table 4), while the Cd-treated groups exhibited symptoms of toxicity; showing inhibited primary root growth and reduced shoot length (Fig. 3a; Table 4). Indeed, the obvious effect of Cd toxicity on rice roots rather than shoots was observed. Seedlings treated with the bacterial inoculant at $1 \times 10^{6} \mathrm{CFU}$ $\mathrm{ml}^{-1}$, in the absence of $\mathrm{CdCl}_{2}$, exhibited normal root elongation and somewhat enhanced fibrous root number. Upon $\mathrm{Cd}$ exposure, the enriched consortia-inoculated seedlings markedly enhanced root length and fibrous root number, and moderately increased shoot length, compared with uninoculated seedlings (Fig. 3a, b). Particularly, the addition of enriched consortia inoculant obviously enhanced the length of roots and number of fibrous roots by 2.1 - and 12-times, and by 1.9- and 18-times, respectively, in rice seedlings exposed to $50 \mathrm{ppm}$ and $100 \mathrm{ppm}$ Cd when compared to the uninoculated group, but the addition of Bacillus cereus did not (Table 4). A bacterial inoculant at $1 \times 10^{6} \mathrm{CFU}$ $\mathrm{ml}^{-1}$ could alleviate phytotoxicity, as evidenced by promoted rice germination and seedling growth even under Cd stress.

Table 4. Effect of indigenous Cd-resistant bacterial consortia $(B C)$ on 7-day rice germination of the Thai rice PSL2 on filter paper system containing $\mathrm{CdCl}_{2}$ at 50 or 100 ppm, with Bacillus cereus as control

\begin{tabular}{c|c|c|c}
\hline Treatment & $\begin{array}{c}\text { Root length } \\
\text { (cm in average) }\end{array}$ & $\begin{array}{c}\text { Shoot length } \\
\text { (cm in average) }\end{array}$ & $\begin{array}{c}\text { No. of fibrous root } \\
\text { (in average) }\end{array}$ \\
\hline Control & $7.5 \pm 2.8$ & $4.6 \pm 2.6$ & $28 \pm 7.4$ \\
Bacillus cereus & $6.2 \pm 2.2$ & $4.2 \pm 2.3$ & $26 \pm 7.2$ \\
$50 \mathrm{ppm} \mathrm{CdCl}_{2}$ & $2.8 \pm 0.8^{* *}$ & $3.2 \pm 0.6^{* *}$ & $2 \pm 1.1^{* *}$ \\
$50 \mathrm{ppm} \mathrm{CdCl}+$ B. cereus & $1.8 \pm 0.5^{* *}$ & $3.1 \pm 0.7^{* *}$ & $2 \pm 1.4^{* *}$ \\
\hline $\mathrm{Control}_{\mathrm{Cd}-\mathrm{resistant} \mathrm{BC}}$ & $7.5 \pm 2.8$ & $4.6 \pm 2.6$ & $28 \pm 7.4$ \\
$50 \mathrm{ppm} \mathrm{CdCl}_{2}$ & $7.1 \pm 2.2$ & $4.5 \pm 2.4$ & $35 \pm 9.8$ \\
$50 \mathrm{ppm} \mathrm{CdCl}+\mathrm{BC}$ & $5.8 \pm 0.8^{* *}$ & $3.2 \pm 0.6^{* *}$ & $2 \pm 1.1^{* *}$ \\
$100 \mathrm{ppm} \mathrm{CdCl}_{2}$ & $2.2 \pm 0.6^{* *}$ & $4.0 \pm 2.4$ & $1 \pm 1.8^{* *}$ \\
$100 \mathrm{ppm} \mathrm{CdCl} \mathrm{Cl}_{2}+\mathrm{BC}$ & $4.1 \pm 1.3^{\# \#}$ & $3.6 \pm 0.4^{* *}$ & $18 \pm 8.3^{\# \#}$ \\
\hline
\end{tabular}

**Indicates significant difference at $P$-value $\leq 0.05$, by comparing the selected parameters of Cd-treated group to that of control (untreated group), and \#\# indicates significant difference at $P$-value $\leq 0.05$, by comparing the selected parameters of bacteria inoculated group to that of uninoculated group in presence of $\mathrm{CdCl}_{2}$ at indicated concentrations. $\mathrm{BC}$ indicates $\mathrm{Cd}$-resistant bacterial consortia after Cd-added culture enrichment

\section{Effect of Cd-resistant consortia on biomass and Cd accumulation of rice tissues toward high-concentration $C d$ in vitro}

In absence of $\mathrm{Cd}$, the enriched consortia enhanced biomass production of shoot and particularly root of Thai rice PSL2 seedlings. The exogenous addition of $\mathrm{Cd}$ at $100 \mathrm{ppm}$ decreased root and shoot dry biomass of rice by 16.1 and $44.5 \%$, respectively, compared to control (Table 5). However, within 14 days of exposure the microbial consortia- 
inoculated seedlings significantly $(p>0.05)$ increased both root and shoot dry biomass at least at one concentration of $\mathrm{CdCl}_{2}(50$ or $100 \mathrm{ppm})$ as compared to the Cd-treated group alone (Table 5). Our result indicated that the inoculation with enriched consortia at $1 \times$ $10^{6} \mathrm{CFU} \mathrm{ml^{-1 }}$ positively affected root biomass production and moderately influenced the shoot length upon high $\mathrm{Cd}$ exposure level.
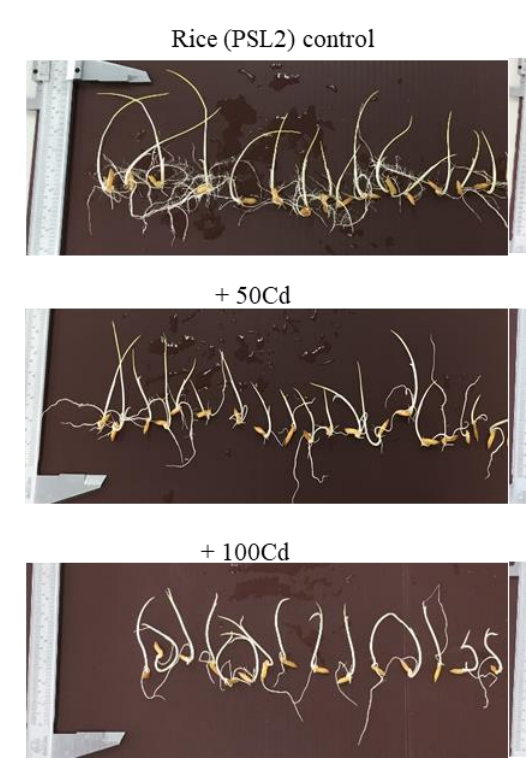

$+\mathrm{BC}$

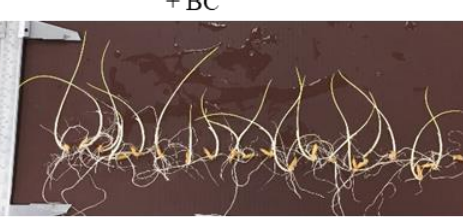

$+50 \mathrm{Cd}+\mathrm{BC}$

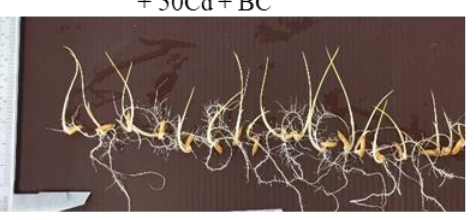

$+100 \mathrm{Cd}+\mathrm{BC}$

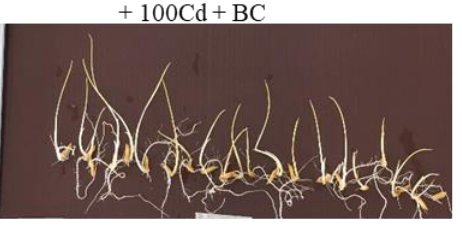

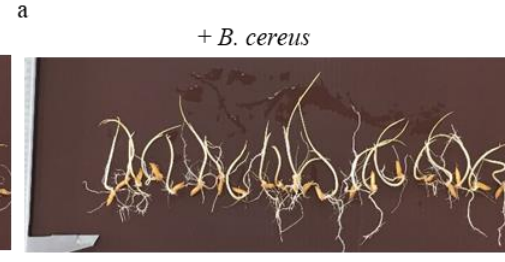

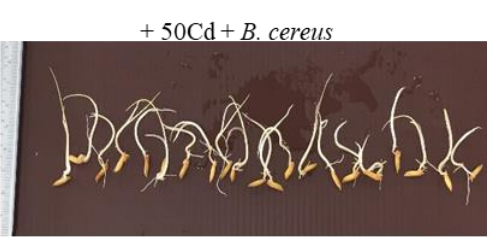

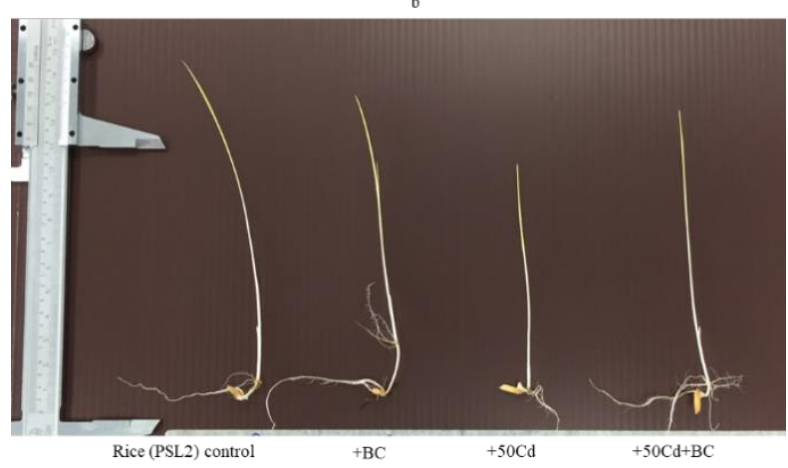

Figure 3. Effect of indigenous Cd-resistant bacterial consortia (BC) on (a) 7-day rice germination in filter paper cultures containing $\mathrm{CdCl}_{2}$ at 50 or 100 ppm, with use of Bacillus cereus as control bacteria, and on (b) 14-day representative growth of rice seedling inoculated

with the bacterial consortia in absence or presence of Cd at 50 ppm, as compared to the uninoculated bacterial consortia

Cadmium content in rice root and shoot was influenced by exogenous addition of $\mathrm{Cd}$; however, the inoculation of enriched consortia remarkably ameliorated $\mathrm{Cd}$ accumulation in rice tissues even at the initial seedling stage (Table 5). Cadmium accumulation in rice root and shoot significantly $(p>0.05)$ decreased when the treatment with enriched consortia at both levels of Cd exposure (50 and $100 \mathrm{ppm}$ ). Notably, the inoculation with enriched consortia at $1 \times 10^{6} \mathrm{CFU} \mathrm{ml}{ }^{-1}$ led to mitigated metal phytotoxicity due to reduced $\mathrm{Cd}$ bioconcentration and promoted biomass production in rice seedlings toward high $\mathrm{Cd}$ exposure level, as summarized in Figure 4. 
Table 5. Effect of indigenous Cd-resistant bacterial consortia $(B C)$ on 14-day rice shoot and root dry biomass and $C d$ content in solution system containing $C d C l_{2}$ at 50 or 100 ppm, with Bacillus cereus as control

\begin{tabular}{c|c|c|c|c}
\hline Treatment & $\begin{array}{c}\text { Root dry biomass } \\
(\mathbf{m g})\end{array}$ & $\begin{array}{c}\text { Shoot dry biomass } \\
(\mathbf{m g})\end{array}$ & $\begin{array}{c}\text { Root Cd content } \\
\left(\mathbf{m g ~ k g}^{-1}\right)\end{array}$ & $\begin{array}{c}\text { Shoot Cd content } \\
\left(\mathbf{m g ~ k g}^{-1}\right)\end{array}$ \\
\hline Rice (PSL2) control & $14.2 \pm 2.0$ & $41.4 \pm 4.8$ & - & - \\
Bacillus cereus & $13.3 \pm 1.4$ & $38.2 \pm 1.7$ & - & - \\
$50 \mathrm{ppm} \mathrm{CdCl}_{2}$ & $13.9 \pm 1.9(1.3 \%)$ & $31.2 \pm 3.5(24.6 \%)$ & $85.3 \pm 1.3$ & $43.2 \pm 1.7$ \\
$50 \mathrm{ppm} \mathrm{CdCl}+$ B. cereus & $14.0 \pm 2.6$ & $33.0 \pm 1.7$ & $90.8 \pm 1.4$ & $45.3 \pm 1.4$ \\
\hline Control & $14.2 \pm 2.0$ & $41.4 \pm 4.8$ & - & - \\
Cd-resistant BC & $25.4 \pm 4.4$ & $44.4 \pm 3.2$ & - & - \\
$50 \mathrm{ppm} \mathrm{CdCl}_{2}$ & $13.9 \pm 1.9(1.3 \%)$ & $31.2 \pm 3.5(24.6 \%)$ & $85.3 \pm 1.3$ & $43.2 \pm 1.7$ \\
$50 \mathrm{ppm} \mathrm{CdCl}_{2}+\mathrm{BC}$ & $23.9 \pm 3.5^{\# \#}$ & $35.5 \pm 2.7$ & $51.2 \pm 1.9^{\# \#}$ & $30.5 \pm 1.6^{\# \#}$ \\
$100 \mathrm{ppm} \mathrm{CdCl}_{2}$ & $11.9 \pm 0.7(16.1 \%)$ & $23.0 \pm 5.3 *(44.5 \%)$ & $162.1 \pm 1.5$ & $72.6 \pm 2.0$ \\
$100 \mathrm{ppm} \mathrm{CdCl}_{2}+\mathrm{BC}$ & $19.8 \pm 1.8^{\# \#}$ & $34.07 \pm 1.6^{\# \#}$ & $99.9 \pm 2.2^{\# \#}$ & $54.0 \pm 1.1^{\# \#}$ \\
\hline
\end{tabular}

**Indicates significant difference at $P$-value $\leq 0.05$, by comparing the selected parameters of Cd-treated group to that of control (untreated group), and \#\# indicates significant difference at $P$-value $\leq 0.05$, by comparing the selected parameters of bacteria inoculated group to that of uninoculated group in presence of $\mathrm{CdCl}_{2}$ at indicated concentrations. Numbers in bracket represents percentage of decrease in plant dry biomass of Cd-treated group relative to control. BC indicates Cd-resistant bacterial consortia after $\mathrm{Cd}$-added culture enrichment

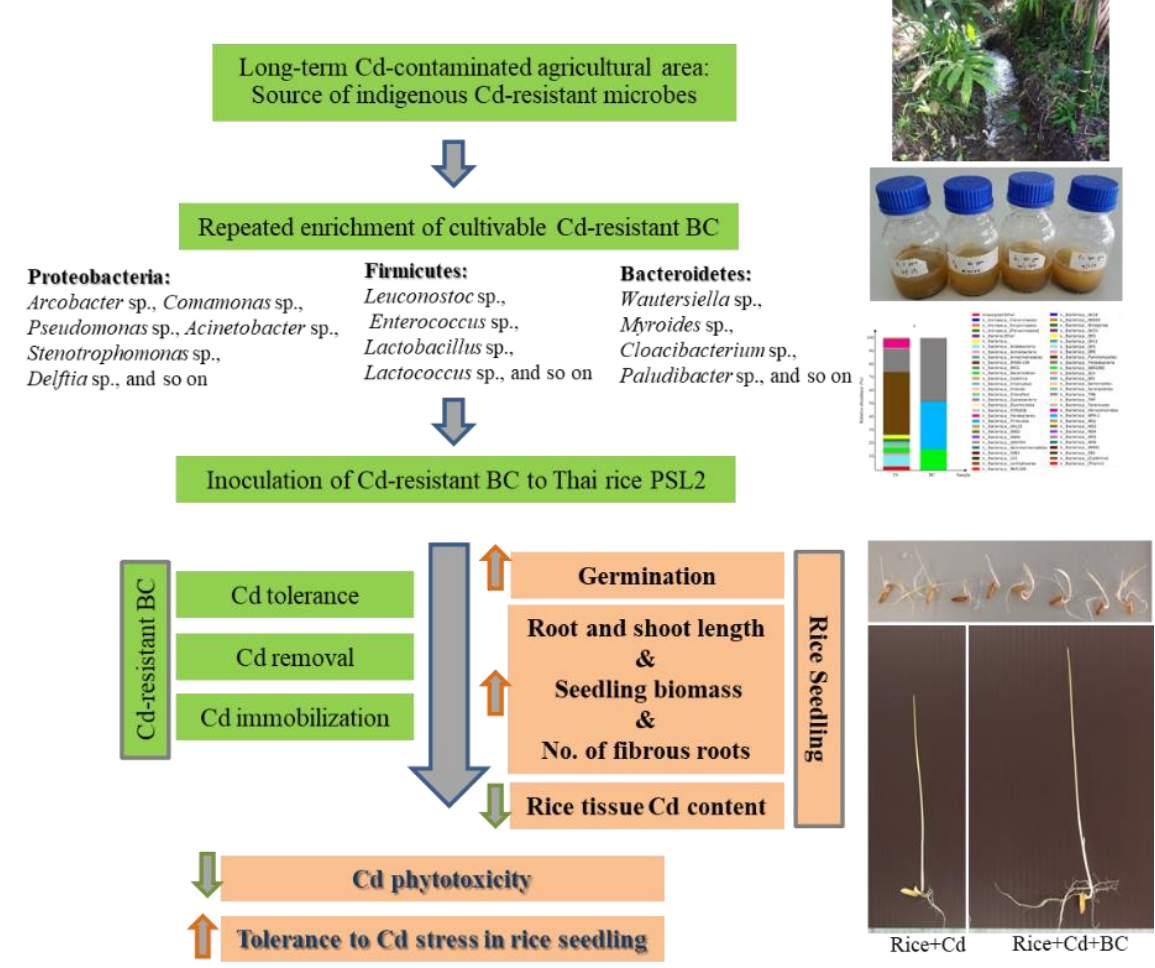

Figure 4. Scheme illustrating the mitigation of $C d$ stress by inoculation of indigenous $C d$ resistant soil bacterial consortia $(B C)$ in seedlings of Thai rice cultivar PSL2 under high Cd exposure level. Due to the Cd tolerance and removal properties of microbial inoculants, $C d$ phytotoxicities were alleviated as evidenced by increased seedling germination and growth as well as lower Cd accumulation in rice tissues. The top phyla including Proteobacteria (47.7\%)

Firmicutes (36.5\%) and Bacteroidetes (15.5\%) were enriched accounting for $99.7 \%$ of total bacterial sequences 


\section{Discussion}

Inoculation of plant inhabiting extreme environments (such as Cd-polluted soils) with specific metal resistant microorganisms could allow them to be more tolerant to high metal stress (Sharma and Archana, 2016). Selection of these metal resistant microorganisms which are capable of promoting plant growth in contaminated environments and minimizing accumulation of metal in edible parts is our intention. Out of concern for the $\mathrm{Cd}$ contamination in agricultural areas of Western Thailand and its effects on human health, indigenous soil microbial consortia with high Cd tolerance were herein screened for potential application to reduce $\mathrm{Cd}$ accumulation in rice tissues. This experiment was designed with the idea that these indigenous Cd-resistant microorganisms have high intrinsic fitness to the local area, and cause minimum disturbance to the local micro-ecological niche.

In this study, indigenous Cd-resistant soil microbial consortia that were successfully enriched on media successively supplemented with $\mathrm{Cd}$ had a maximum tolerance to $\mathrm{Cd}$ of $800 \mathrm{ppm}$ while the selected single strains mostly exhibited much lower tolerance to $\mathrm{Cd}$. Microbial growth was primarily inhibited upon $\mathrm{Cd}$ exposure, but the consecutive addition of $\mathrm{Cd}$ could induce microbial tolerance to this metallic element. The tolerance to higher $\mathrm{Cd}$ levels might be attributed to several tolerance mechanisms, including biosorption, intracellular/extracellular sequestration, complexation, and active efflux (Gadd, 2004; Sharma and Archana, 2016). Indeed, microbial consortia in microenvironments are mostly present as biofilms, which promotes resistance of microbial cells by forming a protective sheath, as well as transforming toxic metal ions into non-toxic forms after biosorption (Hall-Stoodley et al., 2004). Certain metal resistant plant-growth promoting microorganisms can excrete extracellular polymeric substances (e.g., polysaccharides, glycoproteins and lipopolysaccharide) and consequently stimulate biofilm formation in response to toxic metal, as well as facilitating the plant to obtain more water and nutrients. In addition to biosorption, bioaccumulation has a major role in heavy metal uptake and further detoxification by metal-resistant plant-growth promoting microorganisms. Moreover, the enriched consortia had much higher $\mathrm{Cd}$ removal capacities. They also showed in vitro ability to promote rice germination, growth, and biomass production at the seedling stage; however, whether these traits would be active in the paddy field depends on their survival in the natural conditions and capability to colonize rice roots.

Upon high Cd exposure (50 or $100 \mathrm{ppm}$ ), the inoculation with enriched Cd-resistant microbial consortia to PSL2 rice (Oryza sativa L.) enhanced root length and biomass and fibrous root number particularly, and moderately increased shoot length and biomass, compared with the uninoculated seedlings. The increase in root biomass and development of numerous fibrous roots might improve plant performance by extracting more water and nutrients, and consequently promote plant growth under Cd stress (Ahmad et al., 2014). As previously evidenced by the root and shoot biomass data, the inoculation of a metal-resistant Pseudomonas sp. bacterium was regarded as an effective approach for protecting plants against toxic metals (Rajkumar and Freitas, 2008). Pseudomonas spp. belonging to the plant growth-promoting bacterial group is capable of heavy metal biosorption and bioaccumulation, consequently reducing the metal phytotoxicity to the plant (Zaidi and Musarrat, 2004). Similar to our study, the inoculation by enriched Cdresistant microbes ameliorated Cd toxicity and promoted germination of rice seedlings. The microbial load at $1 \times 10^{6} \mathrm{CFU} \mathrm{ml^{-1 }}$ could enhance rice germination and seedling growth even at high $\mathrm{Cd}$ exposure level. 
Our finding was consistent with a previous study that reported that monocotyledonous plants under stressful conditions generally develop a shallow and fibrous root network, enabling them to anchor and efficiently collect surface water (Uraguchi and Fujiwara, 2012). Siripornadulsil and Siripornadulsil (2013) demonstrated that Cupriavidus taiwanensis isolates enhanced fibrous root growth and shoot length in rice seedlings, as well as enhancing germination under Cd exposure. Notably, the enriched consortia had significant $(p>0.05)$ ability to reduce metal phytotoxicity in terms of root and shoot elongation, even at high Cd level (50 ppm). Lee et al. (2010) have revealed increased levels of Glutathione (GSH) and oxidative stress-responsive proteins in the rice root in response to Cd stress. Furthermore, the enriched consortia increased metal tolerance in rice seedlings, as shown by the increase in root and shoot biomass production. Our study demonstrated that the indigenous Cd-resistant microbial consortia isolated from long term Cd-contaminated agricultural area of Western Thailand performed well with the Thai rice PSL2 cultivar widely-cultivated in this area. The inoculation of high metal-resistant and bioaccumulating microorganisms might hold promise to improve plant tolerance to metal stress.

Using 16S next generation sequencing, 3 top phyla including Proteobacteria (47.7\%) Firmicutes (36.5\%) and Bacteroidetes (15.5\%) were detected across the culture enrichment period and accounted for $99.7 \%$ of total bacterial sequences. In the enriched consortia, predominant genera of detoxifiers of Proteobacteria (including Arcobacter sp., Comamonas sp., Pseudomonas sp., Acinetobacter sp., Stenotrophomonas sp., and Delftia sp.), Firmicutes (including Leuconostoc sp., Enterococcus sp., Lactobacillus sp., and Lactococcus sp.), and Bacteroidetes (including Wautersiella sp., Myroides sp., Cloacibacterium sp., Paludibacter sp.) were identified, among other genera. Bacteroidetes is regarded as a soil health indicator, and the prevalence of certain Proteobacteria and Firmicutes is positively associated with soil-borne disease suppressiveness (Sanguin et al., 2009). Previous reports have documented Cd resistance, bioaccumulation and biotransformation in microorganisms belonging to the Acinetobacter, Agrobacterium, Arthrobacter, Bacillus, Cupriavidus, Flavobacterium, Mycobacterium, Pseudomonas, Rhotococcus, Aspergillus, and Trichoderma genera (Belimov and Dietz, 2000; Belimov et al., 2005; Roane and Pepper, 2000; Siripornadulsil and Siripornadulsil, 2013). Certain metal-resistant microorganisms, such as Pseudomonas, Cupriavidus, Bacillus and Acinetobacter, confer beneficial properties for plant growth and development (e.g., nitrogen fixation, phosphate solubilization, and phytohormones production). Recently, an isolated strain of Delftia sp. could stabilize Cd by intracellular bioaccumulation, and thereby decrease $\mathrm{Cd}$ accumulation in rice grains (Liu et al., 2018). Above mentioned microbial strains would be potentially appropriate for $\mathrm{Cd}$ detoxification and bioremediation of Cd-contaminated soils, as well as sustainable plant growth.

Bacteria habituating in different microenvironments have varying adaptabilities to heavy metals. The currently recognized fundamental mechanisms of heavy metal resistance are: 1) metal biosorption on the bacterial cell wall;2) intracellular sequestration of metal by thiol-rich proteins; 3) extracellular sequestration on biosurfactants; 4) metal complexation by sulfur and phosphate; and 5) metal efflux (Sharma and Archana, 2016). Cadmium resistance of soil bacteria primarily relies on active efflux of metal ions by $\mathrm{P}$ type ATPases, cation diffusion facilitator (CDF) transporters, (cobalt/zinc/cadmium) CzcCBA transporters belonging to the resistance, nodulation, cell division (RND) type efflux pump, and chemiosmotic transporters. P-type ATPases and CDF transporters are 
widely present in various bacterial species, while CBA transporter likely acts as determinant for a high-degree of heavy metal tolerance (Nies, 2003). In Gram-negative bacteria, such as Pseudomonas aeroginosa, Cd efflux is mediated by Czc-based zinc efflux and (nickel/cobalt/cadmium) Ncc-based nickel efflux systems in combination with the proton pump ATPase (Das et al., 2016; Hrynkiewicz et al., 2015). In Gram-positive bacteria, Cd efflux occurs by Cd-exporting P-type ATPase, so called CadA pump, first identified in Staphylococcus aureus (Silver et al., 1989). In addition, CadA-like proteins exist in other Gram-positive bacteria, such as Bacillus sp. and Listeria sp (Bruins et al., 2000). In this respect, detailed mechanistic studies underlying metal-immobilizing and plant growth-promoting capabilities of the target enriched microorganisms under various rice stages would be meaningful for optimization and further achievement of their efficient field performance.

The beneficial effect of these Cd-resistant microbial consortia was obvious, even at the high concentration $\mathrm{Cd}$, as they could remove a certain amount of $\mathrm{Cd}$ (ca. $50 \%$ and higher) and had tolerance to $\mathrm{Cd}$ (up to $800 \mathrm{ppm}$ ). Thus, the utilization of these consortia will be a practical, cost-effective, biotechnological approach, which is an alternative to the hugely difficult or expensive and laborious physicochemical treatment of Cd-polluted paddy soil at a large scale. Regarding our findings, the indigenous Cd-resistant microbial consortia with bioremediating and plant-growth promoting potential would be useful to improve rice crop yield and quality in a sustainable, ecologically friendly manner.

\section{Conclusions}

Taken together, our findings demonstrated that the indigenous Cd-resistant microbial consortia were successfully propagated by repeated enrichment culture. They exhibited good performance on alleviating $\mathrm{Cd}$ phytotoxicity and lowering $\mathrm{Cd}$ bioaccumulation in the Thai rice cultivar (Oryza sativa L.) PSL2, resulting in better plant growth upon high $\mathrm{Cd}$ exposure level. The 3 top phyla represented in the detoxifying consortia included Proteobacteria, Firmicutes, and Bacteroidetes (e.g., Acinetobacter sp., Comamonas sp., Enterococcus sp., and Pseudomonas sp.) but other genera were also present. The enriched consortia showed Cd-removal capacities upon high $\mathrm{Cd}$ exposure level. These results highlight the great promise that such Cd-resistant microbial consortia hold for bioremediation of soils for producing low $\mathrm{Cd}$-accumulating rice; however, further studies of the mechanisms underlying their metal-stabilizing effects resulting in healthy plants and field performance studies should be further undertaken for better understanding and appropriate implementation.

Acknowledgements. This work was supported by a grant from Mahidol University, Thailand under the program titled "Stabilization and bioremediation of cadmium and zinc contaminated soil for sustainable rice cultivation" from the National Research Council of Thailand. Thanks to Faculty of Graduate Studies, Mahidol University, Thailand for English proofreading.

\section{REFERENCES}

[1] Ahmad, I., Akhtar, M. J., Zahir, Z. A., Naveed, M., Mitter, B., Sessitsch, A. (2014): Cadmium-tolerant bacteria induce metal stress tolerance in cereals. - Environmental Science and Pollution Research 21: 11054-11065. 
[2] Ahmad, I., Akhtar, M. J., Asghar, H. N., Ghafoor, U., Shahid, M. (2015): Differential effects of plant growth-promoting Rhizobacteria on maize growth and cadmium uptake. Journal of Plant Growth Regulation 35: 303-315.

[3] Allen, S. E., Grimshaw, H. M., Parkinson, H. M., Quarmby, J. A. (1974): Chemical Analysis of Ecological Materials. - Blackwell, Oxford.

[4] APHA, AWWA, WEF (2005): Standard Methods for the Examination of Water and Wastewater. - Public Health Association, Washington, DC.

[5] Belimov, A., Dietz, K. (2000): Effect of associative bacteria on element composition of barley seedlings grown in solution culture at toxic cadmium concentrations. Microbiology Research 155: 113-121.

[6] Belimov, A. A., Safronova, V. I., Sergeyeva, T. A., Egorova, T. N., Matveyeva, V. A., Tsyganov, V. E., Borisov, A. Y., Tikhonovich, I. A., Kluge, C., Preisfeld, A., Dietz, K. J., Stepanok, V. V. (2001): Characterisation of plant growth-promoting rhizobacteria isolated from polluted soils and containing 1-aminocyclopropane-1-carboxylate deaminase. Canadian Journal of Microbiology 47: 642-652.

[7] Belimov, A. A., Hontzeasb, N., Safronovaa, V. I., Demchinskayaa, S. V., Piluzzac, G., Bullittac, S., Glick, B. R. (2005): Cadmium-tolerant plant growth-promoting bacteria associated with the roots of Indian mustard (Brassica juncea L. Czern.). - Soil Biology and Biochemistry 37: 241-250.

[8] Bernard, A. (2008): Cadmium and its adverse effects on human health. - Indian Journal of Medical Research 128: 557-564.

[9] Blake, G. R. (1965): Bulk Density. - In: Black, C. A. (ed.) Methods of Soil Analysis. Part I: Physical and Mineralogical Properties, including Statistics of Measurement and Sampling. American Society of Agronomy, Madison, WI, pp. 374-395.

[10] Bray, R. H., Kurtz, L. T. (1945): Determination of total, organic and available forms of phosphorus in soil. - Soil Science 59: 39-45.

[11] Bruins, M. R., Kapil, S., Oehme, F. W. (2000): Microbial resistance to metals in the environment. - Ecotoxicology and Environmental Safety 45: 198-207.

[12] Brunk, C., Jones, K., James, T. (1979): Assay for nanogram quantities of DNA in cellular homogenates. - Analytical Biochemistry 92: 497-500.

[13] Caporaso, J. G., Kuczynski, J., Stombaugh, J., Bittinger, K., Bushman, F. D., Costello, E. K., Fierer, N., Peña, A. G., Goodrich, J. K., Godron, J. I. (2010): QIIME allows analysis of high-throughput community sequencing data. - Nature Methods 7: 335-336.

[14] Chen, W. M., Wu, C. H., James, E. K., Chang, J. S. (2008): Metal biosorption capability of Cupriavidus taiwanensis and its effects on heavy metal removal by nodulated Mimosa pudica. - Journal of Hazardous Material 151: 364-371.

[15] Das, S., Dash, H. R., Chakraborty, J. (2016): Genetic basis and importance of metal resistant genes in bacteria for bioremediation of contaminated environments with toxic metal pollutants. - Applied Microbiology and Biotechnology 100: 2967-2984.

[16] Deng, Z., Zhang, R., Shi, Y., Hu, L., Tan, H., Cao, L. (2014): Characterization of Cd-, Pb, Zn-resistant endophytic Lasiodiplodia sp. MXSF31 from metal accumulating Portulaca oleracea and its potential in promoting the growth of rape in metal-contaminated soils. Environmental Science and Pollution Research 21(3): 2346-2357.

[17] Edgar, R. C., Haas, B. J., Clemente, J. C., Quince, C., Knight, R. (2011): UCHIME improves sensitivity and speed of chimera detection. - Bioinformatics 27: 2194-2200.

[18] Etesami, H. (2018): Bacterial mediated alleviation of heavy metal stress and decreased accumulatio of metals in plant tissues: mechanisms and future propects. - Ecotoxicology and Environmental Safety 147: 175-191.

[19] Gadd, G. M. (2004): Microbial influence on metal mobility and application for bioremediation. - Geoderma 122: 109-119.

[20] Govindasamy, V., Senthilkumar, M., Bose, P., Kumar, L. V., Ramdoss, D., Annapurna, K. (2011): Acc Deaminase Containing PGPR for Potential Exploitation in Agriculture. - In: 
Maheshwari, D. K. (ed.) Bacteria in Agrobiology: Plant Nutrient Management. SpringerVerlag, Berlin.

[21] Hall-Stoodley, L., Costerton, J. W., Stoodley, P. (2004): Bacterial biofilms: from the natural environment to infectious diseases. - Nature Reviews Microbiology 2: 95-108.

[22] Herlemann, D. P. R., Labrenz, M., Jurgens, K., Bertilsson, S., Waniek, J. J., Andersson, A. F. (2011): Transitions in bacterial communities along the $2000 \mathrm{~km}$ salinity gradient of the Baltic Sea. - ISME Journal 5: 1571-1579.

[23] Hrynkiewicz, K., Ztoch, M., Kowalkowski, T., Baum, C., Niedojadto, K., Buszewki, B. (2015): Strain-specific bioaccumulation and intracellular distribution of $\mathrm{Cd}^{2+}$ in bacteria isolated from the rhizosphere, ectomycorrhizae, and fruitbodies of ectomycorrhizal fungi. - Environmental Science and Pollution Research 22: 3055-3067.

[24] Ihnat, M. (2000): Metal and Other Elements at Trace Levels in Foods. - In: Horwitz, W. (ed.) Official Methods of Analysis of AOAC International. AOAC International, Maryland.

[25] Kuffner, M., De Maria, S., Puschenreiter, M., Fallmann, K., Wieshammer, G., Gorfer, M., Strauss, J., Rivelli, A. R., Sessitsch, A. (2010): Culturable bacteria from Zn- and Cdaccumulating Salix caprea with differential effects on plant growth and heavy metal availability. - Journal of Applied Microbiology 108: 1471-1484.

[26] Lee, K., Bae, D. W., Kim, S. H., Han, H. J., Liu, X., Park, H. C., Lim, C. O., Lee, S. Y., Chung, W. S. (2010): Comparative proteomic analysis of the short-term responses of rice roots and leaves to cadmium. - Journal of Plant Physiology 167: 161-168.

[27] Liu, Y., Tie, B., Li, Y., Lei, M., Wei, X., Liu, X., Du, H. (2018): Inoculation of soil with cadmium-resistant bacterium Delftia sp. B9 reduces cadmium accumulation in rice (Oryza sativa, L.) grains. - Ecotoxicology and Environmental Safety 163: 223-229.

[28] Mitra, S., Pramanik, K., Ghosh, P. K., Soren, T., Sarkar, A., Dey, R. S., Pandey, S., Maiti, T. K. (2018): Characterization of Cd-resistant Klebsiella michiganensis MCC3089 and its potential for rice seedling growth promotion under Cd stress. - Microbiological Research 210: $12-25$.

[29] Nelson, D. W., Sommers, L. E. (1996): Total Carbon, Organic Carbon, and Organic Matter. - In: Sparks, D. L. (ed.) Methods of Soil Analysis. Part 3: Chemical Methods. SSSA Book Series No. 5. SSSA and ASA, Madison, WI.

[30] Nies, D. H. (2003): Efflux-mediated heavy metal resistance in prokaryotes. - FEMS Microbiology Reviews 27: 313-339.

[31] Rajkumar, M., Freitas, H. (2008): Influence of metal resistant-plant growth-promoting bacteria on the growth of Ricinus communis in soil contaminated with heavy metals. Chemosphere 71: 834-842.

[32] Roane, T. M., Pepper, I. L. (2000): Microbial responses to environmentally toxic cadmium. - Microbiol Ecology 38: 358-364.

[33] Sanguin, H., Sarniguet, A., Gazengel, K., Moënne-Loccoz, Y., Grundmann, G. L. (2009): Rhizosphere bacterial communities associated with disease suppressiveness stages of takeall decline in wheat monoculture. - New Phytology 184: 694-707.

[34] Schloss, P. D., Westcott, S. L., Ryabin, T., Hall, J. R., Hartmann, M., Hollister, E. B., Lesniewski, R. A., Oakley, B. B., Parks, D. H., Robinson, C. J., Sahl, J. W., Stres, B., Thallinger, G. G., Van Horn, D. J., Weber, C. F. (2009): Introducing mothur: open-source, platform-independent, community-supported software for describing and comparing microbial communities. - Applied and Environmental Microbiology 75(23): 7537-7541.

[35] Sharma, P. K., Frenkel, A., Balkwill, L. D. (2008): A new Klebsiella planticola strain (cadmium-1) grows anaerobically at high cadmium concentrations and precipitates cadmium sulphide. - Applied and Environmental Microbiology 66: 3083-3087.

[36] Sharma, R. K., Archana, G. (2016): Cadmium minimization in food crops by cadmium resistant plant growth promoting rhizobacteria. - Applied Soil Ecology 107: 66-78.

[37] Silver, S., Misra, T. K., Laddaga, R. A. (1989): DNA sequence analysis of bacterial toxic heavy metal resistances. - Biological Trace Element Research 21: 145-163. 
[38] Simmons, R. W., Pongsakul, P., Chaney, R. L., Saiyasitpanich, D., Klinphoklap, S., Nobuntou, W. (2003): The relative exclusion of zinc and iron from rice grain in relation to rice grain cadmium as compared to soybean: implications for human health. - Plant and Soil 257: 163-170.

[39] Simmons, R. W., Pongsakul, P., Saiyasitpanich, D., Klinphoklap, S. (2005): Elevated levels of cadmium and zinc in paddy soils and elevated levels of cadmium in rice grain downstream of a zinc mineralized area in Thailand: implications for public health. Environmental Geochemistry and Health 27: 501-511.

[40] Siripornadulsil, S., Siripornadulsil, W. (2013): Cadmium-tolerant bacteria reduce the uptake of cadmium in rice: potential for microbial bioremediation. - Ecotoxicology and Environmental Safety 94: 94-103.

[41] Swaddiwudhipong, W., Limpatanachote, P., Mahasakpan, P., Krintratun, S., Punta, B., Funkhiew, T. (2012): Progress in cadmium-related health effects in persons with high environmental exposure in northwestern Thailand: a five-year follow-up. - Environmental Research 112: 194-198.

[42] Uraguchi, S., Fujiwara, T. (2012): Cadmium transport and tolerance in rice :perspectives for reducing grain cadmium accumulation .- Rice 5(1): 5. http//:dx.doi.org /10.1186/19398433-5-5.

[43] Wani, P. A., Khan, M. S., Zaidi, A. (2007): Cadmium, chromium and copper in greengram plants. - Agronomy for Sustainable Development 27: 145-153.

[44] Zaidi, S., Musarrat, J. (2004): Characterisation and nickel sorption kinetics of a new metal hyper-accumulator Bacillus sp. - Journal of Environmental Science Health A 39: 681-691.

\section{APPENDIX}

Figure A1. Representative map showing the location of the single site for topsoil sampling at Pha Dei village, Phra That Pha Daeng, Mae Sot District, Tak Province, Thailand (N 16 40'35.9" E $\left.98^{\circ} 37^{\prime} 37.4^{\prime \prime}\right)$ and its surrounding with 1:500,000 ratio

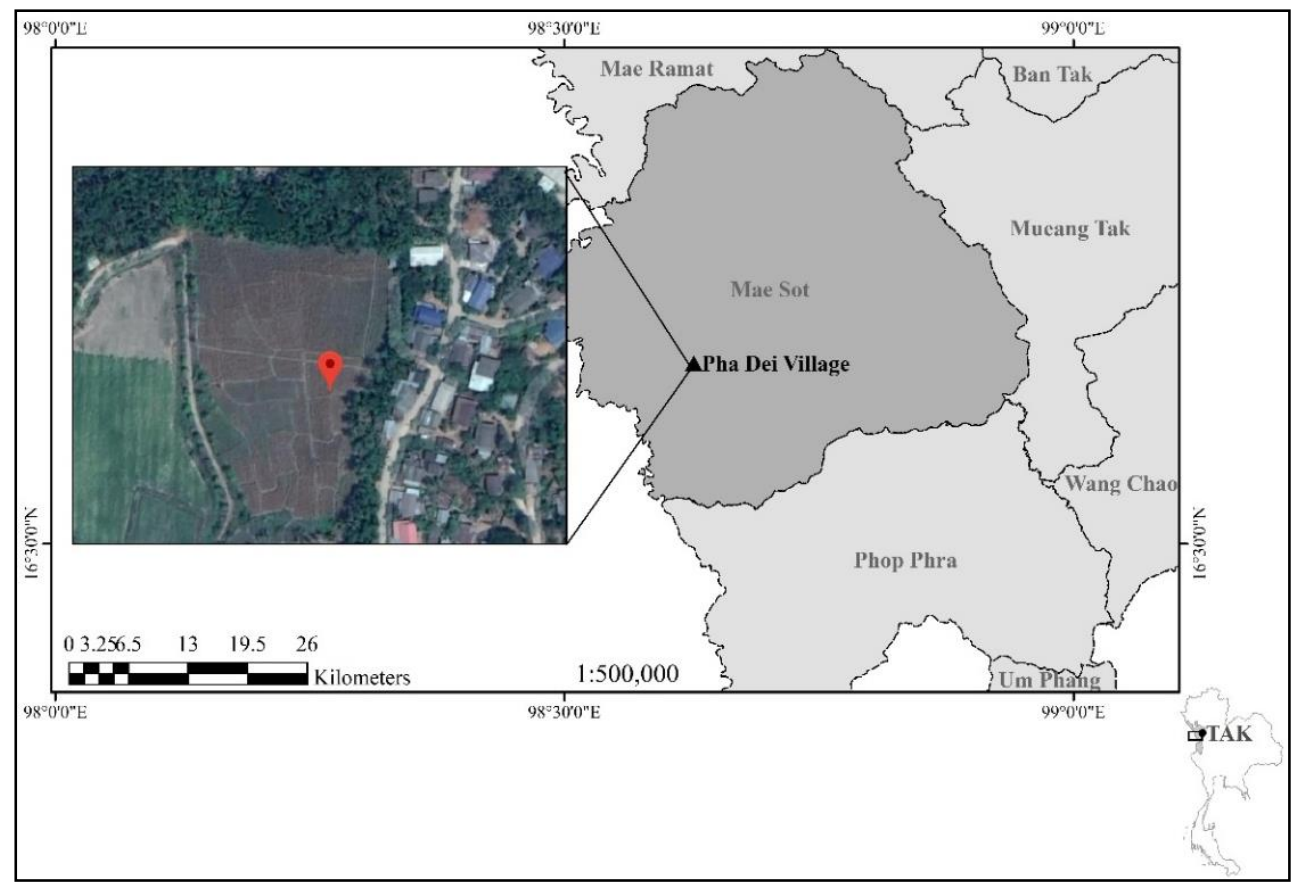


Figure A2. Representative images showing maximum tolerance concentration (MTC) of cadmium of the enriched cadmium-resistant microbial consortia (Cultivable cadmium) on nutrient agar plates with different cadmium chloride concentrations (0, 100, 200, 300, 400, 500, 600, 700, 800, and $1000 \mathrm{ppm}$ )
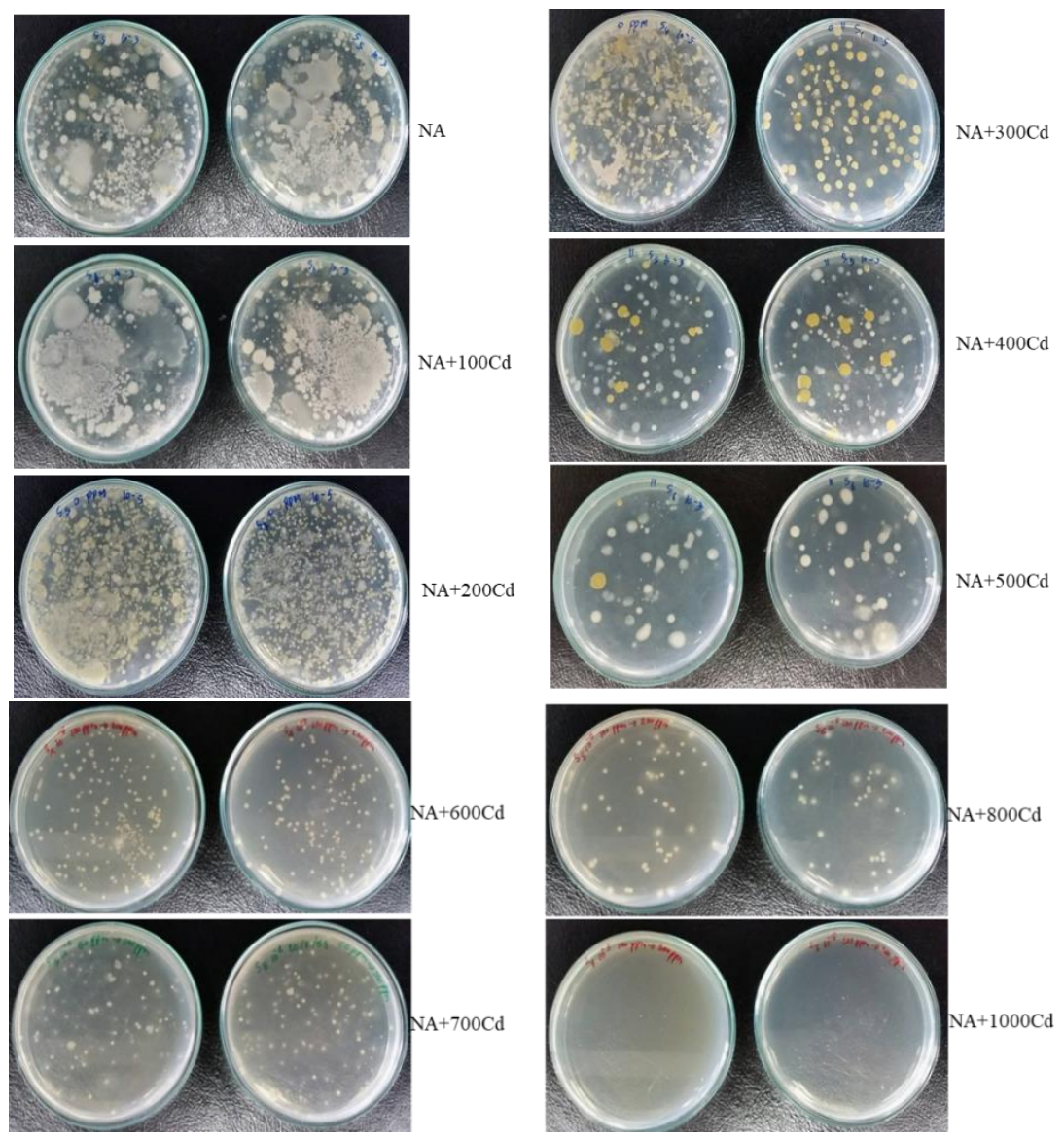

Figure A3. Colony forming and morphology of each cadmium-resistant single strain (Cultivable cadmium) on nutrient agar plates containing 200 ppm cadmium chloride
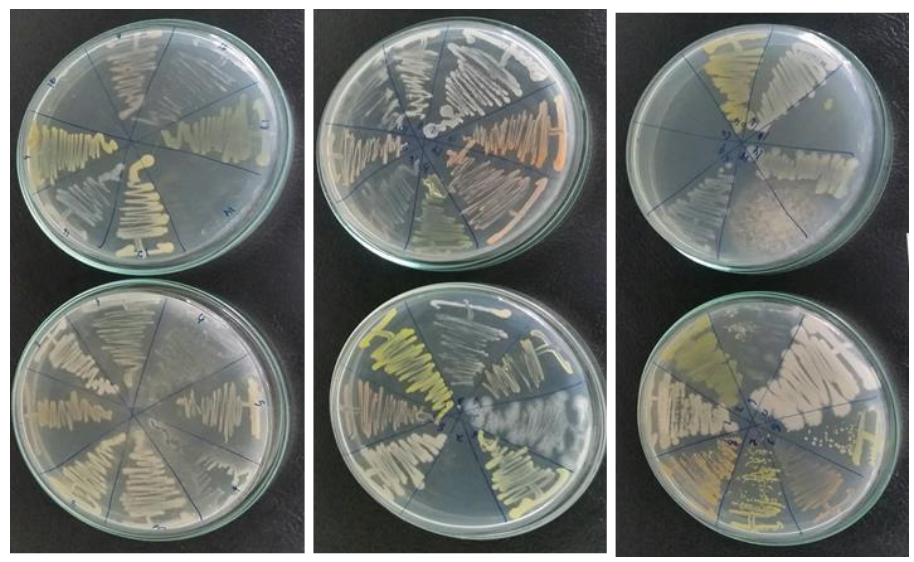